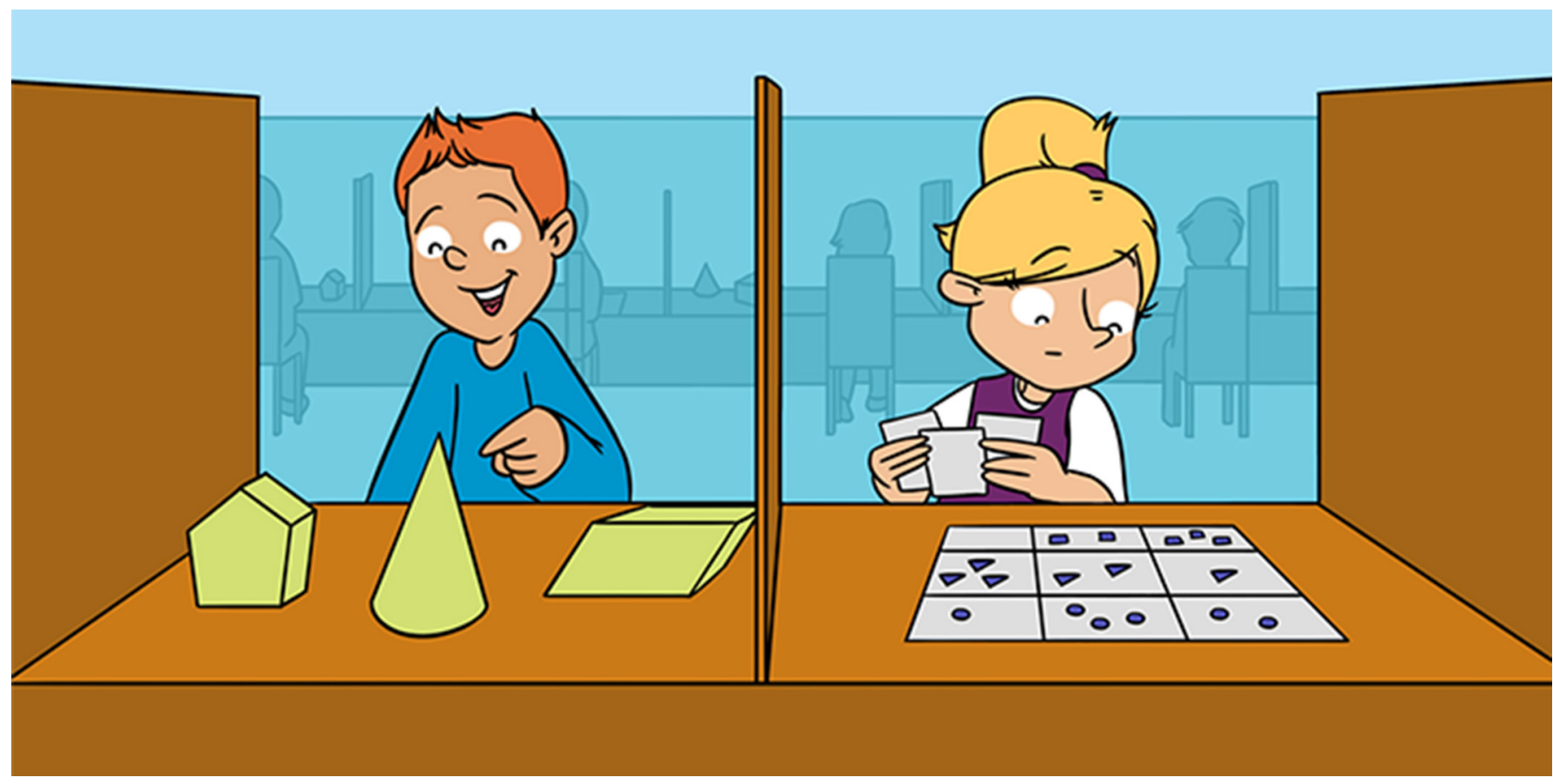

\title{
WHY YOUR MIND IS LIKE A SHARK: TESTING THE IDEA OF MUTUALISM
}

\section{Rogier A. Kievit ${ }^{1 *}$, Ivan L. Simpson-Kent ${ }^{1}$ and Delia Fuhrmann ${ }^{1,2}$}

${ }^{1}$ MRC Cognition and Brain Sciences Unit, University of Cambridge, Cambridge, United Kingdom

²Department of Psychology, Institute of Psychiatry, Psychology \& Neuroscience, King's College London, London, United Kingdom

\section{YOUNG REVIEWERS:}

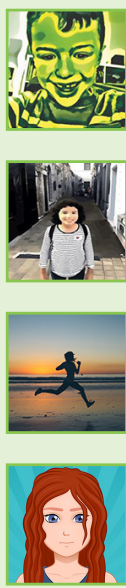

AIDAN

AGE: 9

DANIELA

AGE: 10

LEIMINA

AGE: 11

LUCIE

AGE: 11
We want to understand how children get so much better at certain cognitive abilities like reading, writing, and problem solving as they get older. To better understand this, we followed hundreds of children across a period of years, to see how abilities like problem solving and vocabulary changed over time. We found that having good vocabulary to start with made children's problem solving develop more quickly. It also worked the other way around: being better at problem solving meant children were quicker to learn new words. In other words, each cognitive ability may help other abilities develop. This idea is called mutualism. We were very excited by this discovery, because it can help us understand how children get better at things they never practice directly, and how teachers can better help children who find certain school topics more challenging. 
Figure 1

A suckerfish hitching a ride on a lemon shark (source: Albert Kok, wikimedia).

\section{MUTUALISM}

The idea that different cognitive abilities (such as how many words you know, and how well you can solve problems) actually help each other develop over time.

\section{COGNITIVE}

"Cognitive" is a term scientists use to refer to mental processes like thinking, reasoning, remembering, and problem solving.

\section{VOCABULARY}

This means how many words you know the meanings of.

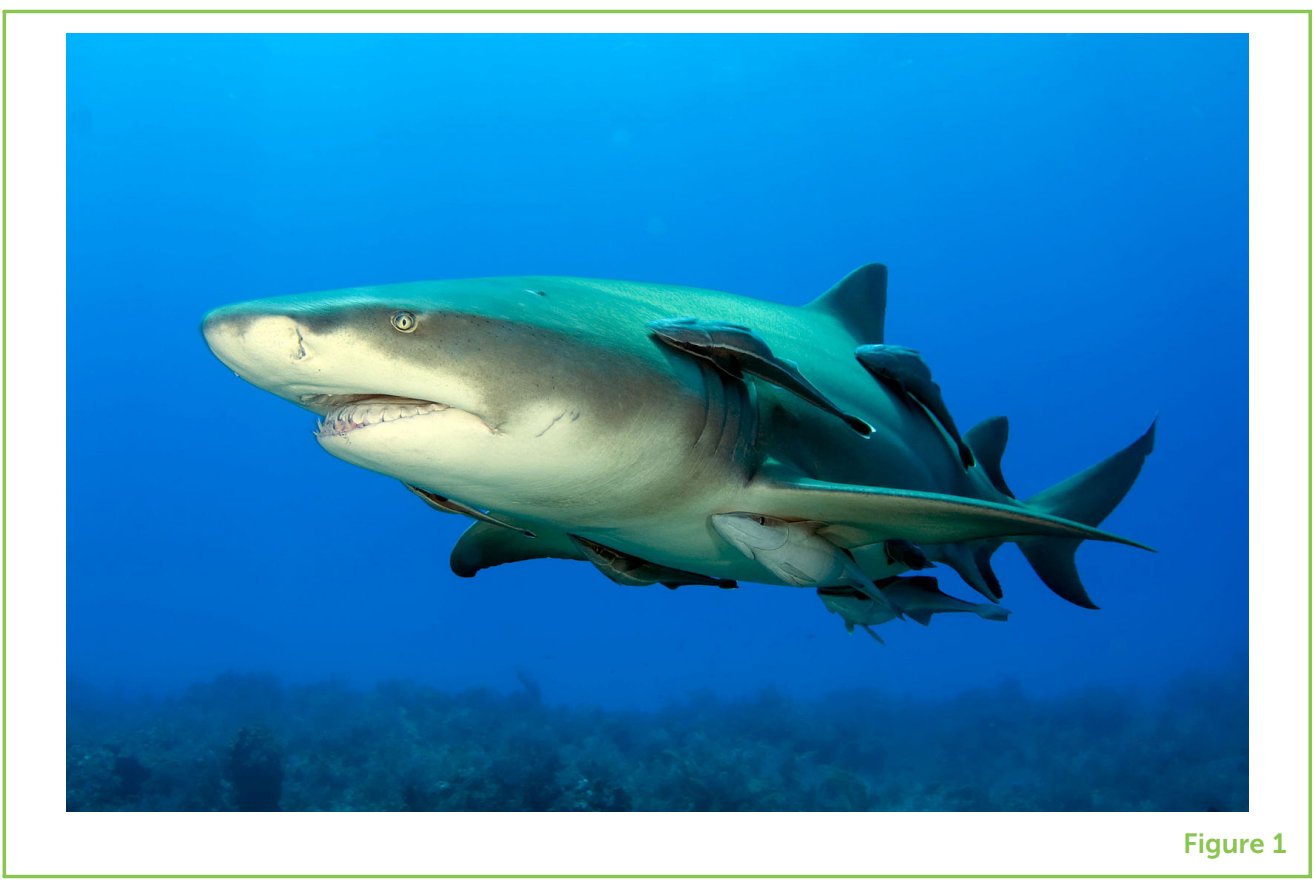

\section{WHAT ANIMALS CAN TEACH US ABOUT OUR MINDS}

One of nature's strangest sights can be found off the coast of Australia: small fish, called suckerfish, or remoras, attach themselves to sharks using a suction cup on their heads (Figure 1-the picture with the shark). Why doesn't the shark just eat the suckerfish? Why does the suckerfish even go near the shark? As it turns out, both animals benefit from this arrangement. The suckerfish eats parasites and dead skin off the shark, helping the shark stay clean and healthy. In return, the suckerfish gets a free ride through the oceans, eats the scraps left over after the shark's meal and is protected from other predators who would not go near the shark-everybody wins! This phenomenon, where both species benefit, is called mutualism. Recently, scientists have used the idea of mutualism to understand something that seems, at first glance, entirely different: human learning.

\section{WHAT IS MUTUALISM?}

Whenever you try to solve a problem-at school or elsewhere-you use what psychologists call your cognitive abilities. Cognitive abilities are things like memory (how well you can remember things from the past), vocabulary (how many words you know) and reasoning (how good you are at solving problems). Many things you do and learn in school rely on cognitive abilities. Vocabulary, for instance, is a really important building block of language, as well as other skills. For example, you use your vocabulary when you apply for a job, tell a story, or write a message to a friend. 


\section{Figure 2}

The idea of mutualism: different cognitive skills help each other grow over time.

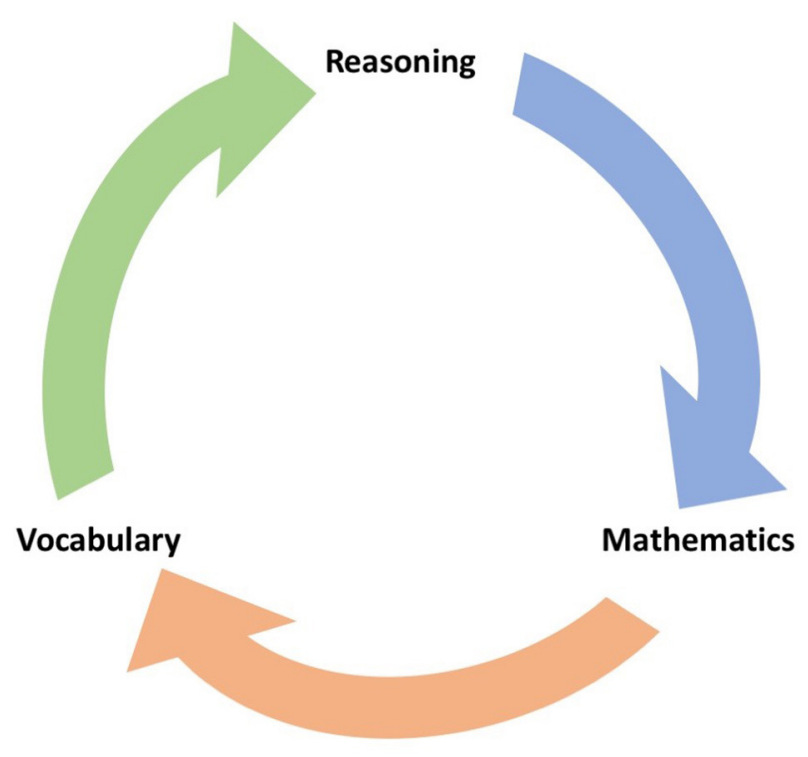

Figure 2

Normally, scientists study different cognitive abilities separately, just like you study lots of different subjects in school. However, in some recent studies, scientists have discovered exciting connections between cognitive abilities. As it turns out, rather than being entirely separate skills, your cognitive abilities behave a bit like sharks and suckerfish-they help each other grow over time. As you can see in Figure 2 (see the picture with the arrows arranged in a circle), your vocabulary is not just useful for improving language skills, it may also help your reasoning, which, in turn, may help your maths skills, which may help your vocabulary. This idea is called mutualism of cognitive abilities [1].

\section{How Can We Test the Idea of Mutualism?}

To test the idea of mutualism, we followed 800 young people (aged 14-24 years) over time and measured their vocabulary and reasoning skills) [2]. In Figure 3, you can see what the vocabulary and reasoning tests looked like. In the vocabulary test, we asked our young people to point out a cone (among other shapes), or explain what a word like "enthusiastic" means. For the reasoning task, we asked young people to fill in the missing puzzle piece (hint: count the shapes from left to right in each row). In our study, the children and adolescents took these tests twice, about 1.5 years apart.

We found that the children and adolescents got a bit better at vocabulary and reasoning over time-just like you get better at most things as you get older. Most importantly, though, we discovered evidence for mutualism of cognitive abilities. It turns out that having a good vocabulary to begin with makes it more likely reasoning improves, and having good reasoning skills to begin with helped with learning more words more quickly. Just like having good balance or 
Figure 3

An example of a vocabulary test (left) and a reasoning test (right) used to study mutualism of cognitive abilities.

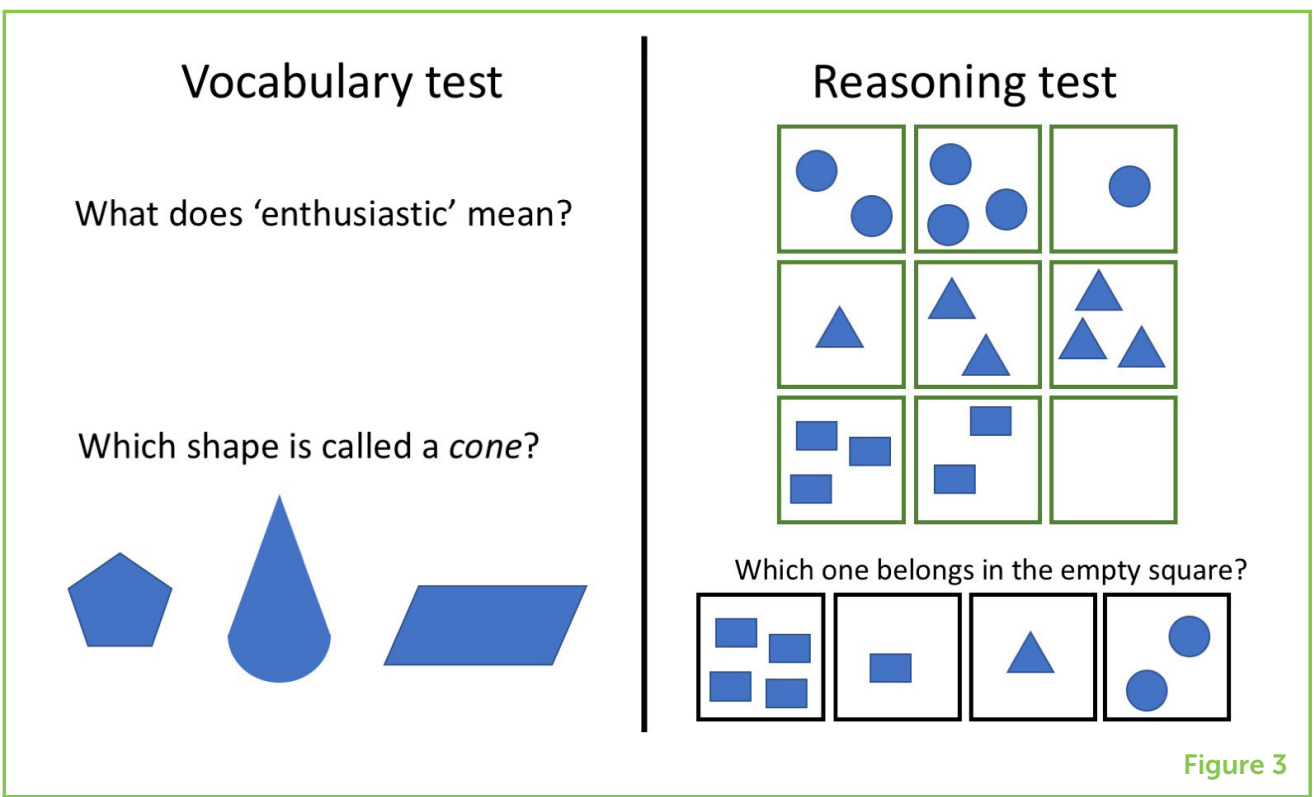

being able to run quickly might help you improve in sports like football or tennis, having good vocabulary and reasoning can help you to develop other cognitive skills as well. To find out whether this finding was reliable, we tested the idea of mutualism in a separate group of young people-this time much younger ( $6-8$ years old). Sure enough, again we found that children with better reasoning abilities made faster improvements in vocabulary, and vice versa [3].

\section{HOW CAN MUTUALISM HELP YOU IN SCHOOL?}

Why could understanding the idea of cognitive mutualism help you? Well, there are several reasons. For example, it may help understand what happens when you learn in school. Two scientists, Stuart Ritchie and Elliot Tucker-Drob, used data from over 600,000 people [4] and found that going to school makes you better at cognitive tests, like $I Q$ tests. This is pretty impressive, given that most of these tests were never taught directly in school. Their findings suggest that going to school actually makes you smarter, even at things you do not directly learn. This is similar to mutualism: having good "building blocks" may allow a range of cognitive abilities develop more quickly.

Understanding mutualism is also useful when you are having a hard time at school. Say you are struggling with maths and you are not sure how to get better. According to mutualism, it might be that getting better at one cognitive ability (like vocabulary) could help you get better at other cognitive abilities, including the one you find harder (like mathematics), even if they seem unrelated. So, do not give up on maths just yet. Working on something else, such as reading, might help boost your maths grades down the line, which in turn could help boost your English grades, which could boost your maths grades, and so on. 
There is even a new study that shows just this: being a little bit better at reading helped kids improve their multiplication skills over time [5]. Therefore, being good at a particular school subject is not just good in and of itself-being good at any subject might help you gain a whole bunch of other skills more easily.

\section{WHAT DID WE LEARN ABOUT OUR MINDS?}

What our research on mutualism shows is that your mind is a bit like the shark and suckerfish: different abilities, like vocabulary and problem solving, actually help each other grow over time. You can think of mutualism as a rule of thumb for learning, both inside and outside the classroom. Mutualism shows the importance of making connections. Both you and your teachers may find it helpful to connect different topics and subjects-what are the links between them, and how can you use what you learned in maths to understand biology? Thinking about, and forming, these connections between topics may help you make the most out of your time at school. Maybe learning about mutualism may even make you think a bit differently about topics at school. It is important not only to study hard, but also as widely as you can. You never know what potential benefits learning one skill will have on the others!

Mutualism is a very new and exciting research field, and there is much left to learn. We are still working hard to understand how it happens in real-life classrooms. We do not know, for instance, whether other cognitive abilities like memory also show the effects of mutualism, whether some children show mutualism more than others, how the brain supports mutualism, or how long you may have to train in reading before you see any benefits in your mathematics. We are working on it though, so stay tuned!

\section{ACKNOWLEDGMENTS}

We would like to thank Callahan Collier (age 11) for valuable feedback on an earlier draft of this manuscript. We would also like to thank those who assisted in the translation of the articles in this Collection to make them more accessible to kids outside English-speaking countries, and for the Jacobs Foundation for providing the funds necessary to translate the articles. For this article, we would especially like to thank RK for the Dutch translation.

\section{ORIGINAL SOURCE ARTICLE}

Kievit, R. A., Hofman, A. D., and Nation, K. 2019. Mutualistic coupling between vocabulary and reasoning in young children: a replication and 
extension of the study by Kievit et al. (2017). Psychol. Sci. 30:1245-52. doi: 10.1177/0956797619841265

\section{REFERENCES}

1. Van Der Maas, H. L., Dolan, C. V., Grasman, R. P., Wicherts, J. M., Huizenga, H. M., and Raijmakers, M. E. 2006. A dynamical model of general intelligence: the positive manifold of intelligence by mutualism. Psychol. Rev. 113:842-61. doi: 10.1037/0033-295X.113.4.842

2. Kievit, R. A., Lindenberger, U., Goodyer, I. M., Jones, P. B., Fonagy, P., Bullmore, E. T., et al. 2017. Mutualistic coupling between vocabulary and reasoning supports cognitive development during late adolescence and early adulthood. Psychol. Sci. 28:1419-31. doi: 10.1177/0956797617710785

3. Kievit, R. A., Hofman, A. D., and Nation, K. 2019. Mutualistic coupling between vocabulary and reasoning in young children: a replication and extension of the study by Kievit et al. (2017). Psychol. Sci. 30:1245-52.

doi: 10.1177/0956797619841265

4. Ritchie, S. J., and Tucker-Drob, E. M. 2018. How much does education improve intelligence? A meta-analysis. Psychol. Sci. 29:1358-69. doi: 10.1177/0956797618774253

5. Rinne, L. F., Ye, A., and Jordan, N. C. 2019. Development of arithmetic fluency: a direct effect of reading fluency? J. Educ. Psychol. 112:110-30. doi: $10.1037 /$ edu0000362

SUBMITTED: 27 September 2019; ACCEPTED: 02 April 2020; PUBLISHED ONLINE: 05 May 2020.

EDITED BY: Sabine Peters, Leiden University, Netherlands

CITATION: Kievit RA, Simpson-Kent IL and Fuhrmann D (2020) Why Your Mind Is Like a Shark: Testing the Idea of Mutualism. Front. Young Minds 8:60. doi: 10.3389/ frym. 2020.00060

CONFLICT OF INTEREST: The authors declare that the research was conducted in the absence of any commercial or financial relationships that could be construed as a potential conflict of interest.

COPYRIGHT (c) 2020 Kievit, Simpson-Kent and Fuhrmann. This is an open-access article distributed under the terms of the Creative Commons Attribution License (CC $\mathrm{BY})$. The use, distribution or reproduction in other forums is permitted, provided the original author(s) and the copyright owner(s) are credited and that the original publication in this journal is cited, in accordance with accepted academic practice. No use, distribution or reproduction is permitted which does not comply with these terms. 

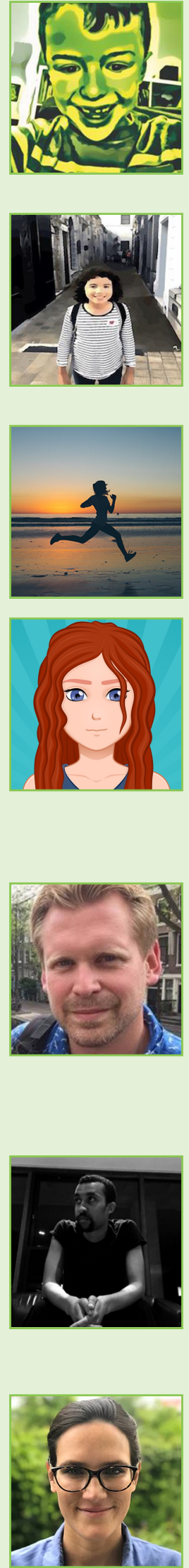

\section{YOUNG REVIEWERS}

\section{AIDAN, AGE: 9}

Aidan is 9 years old, he likes coding and science. He likes to read a lot as well. He likes to read book series like "Wings of Fire," "How to Train Your Dragon," "The Three Doors Trilogy," "Deltora Quest," "His Dark Materials Trilogy," "Mr. Gum," "Harry Potter," and "Weir Do."

\section{DANIELA, AGE: 10}

$\mathrm{Hi}$, my name is Daniela. I am 10 years old. I live in Australia. My favorite hobby is to play tennis, and my favorite subject is science. When I grow up I would like to study science and be a doctor.

\section{LEIMINA, AGE: 11}

$\mathrm{Hi}$, I love sport especially netball, but I also love other sports as well. I would say that I am a pretty good artist. I just love reading and learning new things.

\section{LUCIE, AGE: 11}

Lucie loves science and maths. She is quite interested in biology and chemistry. In her spare time, Lucie likes to read. Her favorite book genres are non-fiction, action, fantasy, and romance.

\section{AUTHORS}

\section{ROGIER A. KIEVIT}

Rogier is a psychologist who wants to understand why children learn skills so quickly, and why older people tend to get a bit worse at things when they grow (really) old. He looks at large groups of children and adults to figure out how their brains change over time, and what those changes do to how they think, reason, and remember. He loves sharks and was very happy he could use a picture of one in this paper. *rogier.kievit@mrc-cbu.cam.ac.uk; www.rogierkievit.com

\section{IVAN L. SIMPSON-KENT}

Ivan is a Ph.D. student at the MRC Cognition and Brain Sciences Unit at the University of Cambridge. His research attempts to understand how the brain and behavior interact with each other during childhood and adolescence to produce intelligence. He hopes to apply insights from his research to help guide education policy, especially for disadvantaged youth struggling to learn in school.

\section{DELIA FUHRMANN}

Delia is a psychologist who is fascinated by how the mind and brain develop. She works at the University of Cambridge and King's College London. She wants to understand how the environment impacts us at different ages. Outside the lab, she likes playing with her kids, reading books, and dancing. 